and the plant may well be built there.

The change of plan became apparent when Mr F. E. Dean, the Gas Corporation's Chief Technical Liaison Officer, wrote to Aberdeen County Council informing it that the alternative planning application was being prepared. The chief reason for the change is said to be that the Ministry of Defence, which already has planning permission to build a radio station on Crimond airfield. above the loch, is still eager to use the site. A Gas Corporation spokesman added this week, however, that the protests from conservationists in the area who were worried that the plant might seriously damage the loch, which the Nature Conservancy classifies as being of grade one scientific importance (see Nature, 242, 93 ; 1973), did have some effect.

The St Fergus site is much less valuable than the Loch of Strathbeg which is Britain's largest dune slack pool. The slack pools, dunes and bird-life at Blackwater, just north of St Fergus, where it is thought the plant will be sited, are far less likely to be disturbed by the station than at the Strathbeg site.

The Gas Corporation was at pains to point out this week that planning application for Crimond has merely gone into abeyance, and if the Blackwater site proves impossible, Crimond may still be the chosen spot. It is unlikely, however, that Total and the Gas Corporation would get the site without a planning inquiry if the Ministry of Defence seriously wants it. Work was due to start on the ministry's radio station this year, with completion planned for 1975 , but the plan to put a gas processing plant on Crimond may have held work up.

\section{BRITISH MUSEUM}

\section{Chaotic Jubilee}

THE British Museum Research Laboratory is celebrating its Golden Jubilee with an exhibition which opened on May 4. At the entrance to the exhibition blowups of several historic press cuttings are displayed in a sepia coloured anteroom simulating the conditions under which the first workers in the laboratory laboured. Among these cuttings is one from the Daily Herald of December 31, 1931:

"I am certain that Dr Alexander Scott (FRS) could put Humpty Dumpty together again. That would be a small job for the head of the laboratory which cleans and restores the priceless exhibits of the British Museum."

So begins the cutting. And perhaps Dr Scott's sure touch would have helped in the preparation of this exhibition, for at the press showing on May 3 the display was still being put together, and seemed to be in about as many pieces as Humpty Dumpty after his fall. That makes it difficult to assess the merits of the exhibition, housed within a double dome inflated by air pressure, in the former ethnography gallery. Undoubtedly the show will be worth a visit in calmer conditions, when it will be possible to see if the rainbow coloured lighting and technological exhibitionism of the surroundings add to, or detract from, the exhibits, which will include the use of radiography, metallography, $\mathrm{X}$-ray diffraction analysis, atomic absorption analysis and both carbon-14 and thermoluminescence dating.

The overall appeal of the exhibition seems likely to be visual rather than scientific. One already complete exhibit, for example, shows a glass vase which appears pea soup green in reflected light and magenta in transmitted light. This effect has been duplicated at the laboratory by adding sundry traces of metallic oxides to glass -but this seems very much window dressing compared with the real work of the laboratory.

It is, however, obvious that the staff of the laboratory has achieved much under difficult conditions. Not only scientific problems but bureaucratic difficulties have confronted them. In another cutting displayed at the show, quoting from the Birmingham Post sometime in 1932, we learn that "The laws and regulations under which museum authorities work are strict. As a precaution against fire and explosion there is no gas on the premises. Some years ago a room was set apart as a laboratory, and a supply of gas became essential, but the regulations could not be broken. The difficulty was overcome by carrying a pipe to the outside of the laboratory window, and then continuing the supply to the desired position by means of a rubber tube that could be disconnected every night".

Also, "No exhibit can be taken away for treatment. Once an exhibit has been accepted by the trustees an Act of Parliament would be necessary to permit its removal from the premises. The laboratory in Russell Square ... . is made technically part of the Museum by a connecting corridor across the grounds. Every article in need of treatment ... has to be carried that way so that there shall be no direct breach of the rules." And seemingly it still requires an Act of Parliament to remove articles from the Museum, for example when exhibits are displayed abroad.

Although when the laboratory was first set up in 1922 Nature commented that "National laboratories for the cleaning, restoration, and preservation of antiquities have for some years existed at Berlin, Copenhagen and Stockholm" $(109,119 ; 1922)$, it is today the oldest museum laboratory in exist- ence. So, having started perhaps somewhat ingloriously, primarily concerned in the first years with the restoration of objects which had been damaged when stored in a section of the Underground during the First World War, the staff have now thoroughly earned their right to a Jubilee junket.

\section{PESTICIDES}

\section{Too Much Concem}

CONCERN about the use of pesticides has sometimes been due to misinterpretation or improper extrapolation of scientific Nata, according to a World Health Organization expert committee on insecticides (Safe Use of Pesticides, Report No. 513, WHO, Geneva, 1973). This has caused some administrations to impose restrictions on the use of certain pesticides which cannot be justified on the basis of present scientific knowledge, says the committee.

The nub of the report is that the advantages of the use of pesticides, in particular DDT, in controlling diseases outweigh their disadvantages. The committee warns that the withdrawal of DDT from areas which in the past have been ravaged with malaria could well see the return of the disease.

But the committee accepts that there is insufficient evidence available on the effects of DDT on man. It recommends that comprehensive metabolic studies be carried out of the effect of the disease to complement studies on the carcinogenicity of the pesticide. The committee points out, however, that even though the first reports that DDT might cause tumours in rats appeared in 1947, there has been no adverse effect observed in a small group of men who have been exposed to heavy doses and who have been under survey for the past twenty years.

Education is the answer to the hysteria caused in recent years by the supposed effects of pesticides according to the committee. The report says that even in developed countries, people need to be introduced to the basic principles of toxicology "in order to dispel the excessive concern over hypothetical but unproven effects of pesticides and to ensure a more realistic appreciation of hazards".

DDT is not the only topic covered in the report and the committee also makes a plea for the introduction of less toxic mercury compounds than those at present used as seed dressings and fungicides. The alkyl mercury compounds, the committee points out, accumulate in the nervous system giving rise to irreversible damage. So, "in the long view, it may be unwise to use any mercury compounds and certain other heavy metal compounds as pesticides". 